\title{
The influence of self-compassion on emotional well-being among early and older adolescent males and females
}

\author{
Karen Bluth ${ }^{\mathrm{a},{ }^{*}}$ and Priscilla W. Blanton ${ }^{\mathrm{b}}$ \\ aProgram on Integrative Medicine, Department of Physical Medicine and Rehabilitation, \\ University of North Carolina, CB \#7200, Chapel Hill, NC 27599, USA \\ bDepartment of Child and Family Studies, University of Tennessee, 1215 W. Cumberland Ave., \\ Knoxville, TN, USA
}

\begin{abstract}
Self-compassion has been associated with well-being in adult samples, but has rarely been assessed in adolescents. In this study, 90 students ages 11-18 completed an online survey assessing self-compassion, life satisfaction, perceived stress and positive and negative affect. Findings indicated that older female adolescents had lower self-compassion than either older male adolescents or early adolescents of either gender, and self-compassion was associated significantly with all dimensions of emotional well-being with the exception of positive affect. Additionally, phase of adolescence, but not gender, was found to moderate the relationship between selfcompassion and dimensions of well-being; for older adolescents, the inverse relationship between self-compassion and negative affect was stronger. Lastly, the influence of the various components of self-compassion was investigated and discussed.
\end{abstract}

\section{Keywords}

self-compassion; adolescence; emotional well-being; self-compassion subscales; gender

The road through adolescence is marked with challenges and transitions. During this developmental stage, individuals are undergoing rapid physiological growth (Blakemore, Berenbaum, \& Liben, 2009, p. 224; Divall \& Radovick, 2008; Susman \& Dorn, 2009) including changes in both structure and function of the brain (Giedd, 2008). Coupled with these physiological changes are the emergence of new cognitive abilities, including the capacity for metacognition and the ability to think abstractly, which promote adolescents' increasingly complex and sophisticated ways of relating to their world (Keating, 2004).

Taken together, such changes often have dramatic effects on the ways in which adolescents perceive, understand, and interpret their daily experiences, particularly those that occur in social and emotional domains.

The demands and pressures of adolescence have extended for an increasingly longer period of time in Westernized cultures. The experiences of those in early adolescence and those in 
later adolescence can vary considerably and many scholars are conceptualizing currently adolescence as a stage of development that encompasses phases. Adolescents are increasingly able to think in terms of possibilities and relativities as they move through the phases of adolescence. Their capacity for critical thinking increases and their ability to formulate their own beliefs and values increasingly develops more fully (Marcia, 1980). Identity exploration, a process central to this stage of development (Erikson, 1968), may stimulate adolescents to self-reflect and to consider their relationships with others, their niche within their peer group, and their role in society. As they compare themselves with their peers, adolescents often engage in self-doubt and self-criticism (Steinberg, 1999), which may contribute to a negative self-image.

Adolescents' advancing cognitive development also makes it possible for them to take the perspectives of others, and in that way, to see themselves through others' eyes. As this transpires, they often become more self-conscious (Elkind, 1967, 1985). Elkind described two phenomena that emerge in this stage of development, the 'imaginary audience' and the 'personal fable'. The 'imaginary audience' reflects adolescents' limited abilities to differentiate between their own thoughts about themselves and their thoughts about others' thoughts (Arnett, 2001) often leading to imagining that there is an engrossed audience observing them. This exaggerated sense of being 'on stage' often results in heightened selfconsciousness and harsher self-criticism. With the related phenomena of the 'personal fable', adolescents believe that the challenges and difficulties that they are experiencing are unique to them. Adolescents often believe that no one can understand them since no one else has endured their experiences; this perception may lead to a sense of isolation, loneliness, depression, and/or anxiety (Elkind, 1978).

The challenges of these developmental processes, coupled with the social pressures and expectations from school and family, may influence the increasing rate of mental and emotional disorders found among adolescents (Kessler, Avenevoli, \& Ries Merikangas, 2001). Indeed, research has shown that $21 \%$ of children and adolescents experience an anxiety disorder (Kashani \& Orvaschel, 1990) and 20-25\% of adolescents experience a depressive disorder before finishing high school (Lewinsohn, Hops, Roberts, Seeley, \& Andrews, 1993), with many others suffering from subclinical symptoms, which hinder diagnosis and treatment (Hammon \& Rudolph, 2003). The prevalence of depression is impacted by both gender and phase of adolescent development according to epidemiological data. The prevalence of depression rises substantially throughout adolescence and a preponderance of this increase occurs with girls (Abela \& Hankin, 2011; Thapar, Collishaw, Pine, \& Thapar, 2012). This gender difference in depression may be associated with a difference in coping styles; females are more likely to ruminate in response to stress, and ruminating has been linked to depression (Nolen-Hoeksema, 2001). Furthermore, due to interference with developmental processes (Johnson \& Greenberg, 2013), mental and emotional disorders in adolescence increase the potential for outcomes such as substance abuse, poor school attendance, violence against themselves or others, and risky behavior (Albano, Chorpita, \& Barlow, 2003; Crocetti, Klimstra, Keijsers, Hale, \& Meeus, 2009; Hammon \& Rudolph, 2003). 
In contrast to these negative conditions that can adversely impact developmental processes, there has been a more recent emphasis on the impact of positive psychological well-being. A more recent emphasis in research efforts has shown that positive psychological states can decrease vulnerability, increase resilience, and enhance the likelihood of positive developmental outcomes in not only adolescence, but also in adulthood (Keyes, Dhingra, \& Simoes, 2010). The perspective of positive psychology emphasizes a focus on strengths and resourcefulness or flourishing, rather than a focus on deficits and problems or floundering during the stage of adolescence. Flourishing has been described as encompassing factors that include positive emotion, engagement with what one is doing, a sense of accomplishment, and good relationships (Seligman, 2012). Only recently has this perspective focused on the enhancement of positive mental health for children and adolescents (Howell, Keyes, \& Passmore, 2013), with little study of positive processes among adolescents (in comparison to that of college students and adults). When positive processes during adolescence such as engaged living have been examined, positive associations have been found with various dimensions of psychological well-being (Froh et al., 2010).

One positive factor that has been shown to be associated with well-being in adults is selfcompassion (MacBeth \& Gumley, 2012). In fact, through welcoming negative emotions rather than resisting or suppressing them, self-compassionate behaviors are posited to engender positive emotions and are associated with psychological strengths (Neff \& Dahm, in press). Self-compassion is theorized to have similar positive effects for adolescents (Neff, 2003a). However, research available on self-compassion among adolescents is very sparse. Following is a description of the construct of self-compassion, as defined by Neff (2003a), and its role in influencing well-being based on current research findings.

Neff defined self-compassion as 'being open to and moved by one's own suffering, experiencing feelings of caring and kindness toward oneself, taking an understanding, nonjudgmental attitude toward one's inadequacies and failures, and recognizing that one's experience is part of the common human experience' (Neff, 2003a, p. 224). She described this construct as being composed of three interrelated and mutually-enhancing components: self-kindness, or treating oneself kindly rather than with harsh criticism; common humanity, entailing a recognition that we are integrally connected with others who are frequently experiencing similar struggles; and mindfulness, or maintaining perspective at challenging times by neither pushing away nor becoming overwhelmed with one's thoughts or feelings (Neff, 2003a). Others have emphasized that self-compassion is based in part on the notion that we are part of a common humanity; as such, we are necessarily aware of the suffering and needs of others (Baer, 2010). In this framework, self-centeredness, and for that matter, the phenomena of the imaginary audience cannot exist concurrently with self-compassion. Thus, self-compassion needs to be examined in terms of the role it may play in adolescents' experiences of positive emotions.

The construct of self-compassion is not to be confused with that self-esteem; the latter often involves a comparison of one's abilities with those of others, resulting in an evaluation or judgment (often negative) about where one stands in the social hierarchy (Neff \& McGehee, 2010). In contrast, self-compassion involves a linking or fundamental connection with others through an understanding of one's common humanity (Neff, 2003a). As such, it would be 
unlikely that one who was high in self-compassion would also strongly exercise the phenomena of the personal fable, in which adolescents believe that they are alone in their experiences. In fact, Neff and McGehee (2010) confirmed a negative correlation between self-compassion and adolescents' experiences of personal fable. As self-criticism, feeling isolated, and exaggerating one's feelings are particularly evident during adolescence, Neff (2003a) suggested that self-compassion may be particularly low at this stage of development, but perhaps instrumental for positive development.

In adult samples, self-compassion has been found to be strongly associated with positive emotional well-being. Results of a recent meta-analysis composed of 14 studies indicated a large effect size for an inverse association of self-compassion with psychopathology, measured by aggregating reported symptoms of depression, anxiety and stress (MacBeth \& Gumley, 2012). Other research findings with adults indicated that self-compassion was associated with many of the factors characterized by positive psychology research (Seligman \& Csikzentmihalyi, 2000) including greater life satisfaction (Neff, 2003b), happiness (Hollis-Walker \& Colosimo, 2011; Neff, Kirkpatrick, \& Rude, 2007; Neff \& Vonk, 2009), optimism (Neff et al., 2007; Neff \& Vonk, 2009), positive affect (Neff et al., 2007; Neff \& Vonk, 2009), wisdom (Neff et al., 2007), emotional intelligence (Heffernan, Quinn Griffin, McNulty, \& Fitzpatrick, 2010; Neff, 2003b), coping skills (Leary, Tate, Adams, Batts Allen, \& Hancock, 2007; Neff, Hsieh, \& Dejitterat, 2005), greater self-improvement in motivation (Breines \& Chen, 2012), and overall psychological well-being (Baer, Lykins, \& Peters, 2012; Neff et al., 2007). Further, self-compassion was associated with healthy social functioning and successful aging among a population of older adults (Allen, Goldwasser, \& Leary, 2012). Among clergy, self-compassion contributed to both higher levels of job satisfaction and lower levels of emotional exhaustion (Barnard \& Curry, 2011). In regard to relationships with others, self-compassion has been found to be positively associated with relational well-being (Neff \& Beretvas, 2013; Neff \& Pommier, 2013; Yarnell \& Neff, 2013). In the only study that used an adolescent sample, the results were similar to results from research conducted with adults. Self-compassion was found to be associated inversely with anxiety and depression and positively with social connectedness (Neff \& McGehee, 2010). Although self-compassion has the potential for promoting positive well-being among adolescents (Neff, 2003a), there is a clear paucity of research in this area that needs to be addressed.

An area of self-compassion research in which there have been inconsistent findings is that of gender comparisons. Several studies have found women to have slightly lower levels of selfcompassion than men (Neff, 2003b; Neff \& Beretvas, 2013; Neff et al., 2005; Neff \& McGehee, 2010; Neff \& Vonk, 2009; Raes, 2010; Yarnell \& Neff, 2013). However, other studies have found no gender differences (Iskender, 2009; Neff et al., 2005, 2007; Neff \& Pommier, 2013). Gender needs to be explored further in self-compassion research in general. In terms of research with adolescents, the role of self-compassion in supporting the well-being of girls in later adolescence is of particular interest since findings support the conclusion that older adolescent girls are particularly vulnerable to depression, and positive well-being during adolescence has been found to be a protective factor in association with depressive symptom-atology (Hoyt, Chase-Lansdale, McDade, \& Adam, 2012). Although Neff and McGehee (2010) did not find gender differences in their adolescent sample, they 
did not examine it at different phases of adolescence as their sample came from a highschool setting. They did, however, find gender differences among their college sample with females reporting less self-compassion than males. Additionally, contrary to Neff and Vonk (2008) who reported a slight increase in self-compassion with adults aged 18-88, Neff and McGehee (2010) found no difference in level of self-compassion between high-school students and college students. Thus, both gender and phase of adolescent development need to be examined in research efforts focused on self-compassion.

Self-compassion is assessed through the Self-Compassion Scale (Neff, 2003a), a scale that taps three dimensions of self-compassion: self-kindness, common humanity, and mindfulness. Each dimension is operationalized through two subscales which theoretically describe the positive and negative aspects of the dimension, i.e. self-kindness and selfjudgment, common humanity and isolation, mindfulness and over-identification (i.e. becoming carried away with one's emotions). However, it is important to keep in mind that the two subscales measuring one dimension are not necessarily opposite ends of a continuum in that it is theoretically possible for an individual to be high in self-kindness without necessarily being low in self-judgment (Neff, 2003b).

\section{Self-compassion subscale research}

To investigate which components of self-compassion are driving the association with wellbeing, recent research has deconstructed the self-compassion scale into its component subscales and explored relationships between the subscales and outcome measures. Results indicated that all three negatively worded subscales (self-judgment, isolation, and overidentification) were positively associated with anxiety, depression, worry, stress, and paranoid beliefs (Brooks, Kay-Lambkin, Bowman, \& Childs, 2012; Mills, Gilbert, Bellew, McEwan, \& Gale, 2007; Van Dam, Sheppard, Forsyth, \& Earleywine, 2011; Ying, 2009) and negatively with sense of coherence and self-efficacy (Iskender, 2009; Van Dam et al., 2011; Ying, 2009). In addition, self-judgment and isolation have been found to be inversely associated with quality of life, while self-kindness and mindfulness have been positively associated with quality of life (Van Dam et al., 2011). Further, isolation has been found to be inversely associated with positive well-being (Hollis-Walker \& Colosimo, 2011). The positive subscales (self-kindness, common humanity, and mindfulness) were found to be inversely associated with depression (Mills et al., 2007; Van Dam et al., 2011; Wong \& Mak, 2012; Ying, 2009) and positively with sense of coherence and self-efficacy (Iskender, 2009; Ying, 2009). In several studies with undergraduates and masters' level social work students, it appeared that the strength of the correlations for the negatively worded subscales were stronger than those of the positively worded subscales (Mills et al., 2007; Ying, 2009), but no information was offered to explain these results. Although the aforementioned results on the sub-scale associations contribute to the self-compassion literature, this aspect of selfcompassion research is still in its infancy. In fact, further research has been called for with greater attention being given to the self-compassion subscales in order to bring clarity to the components of self-compassion that are associated with a particular outcome (MacBeth \& Gumley, 2012; Wong \& Mak, 2012). 
To address the lack of research on self-compassion among adolescents, the current study was guided by the following research questions:

1. Is self-compassion related to dimensions of well-being among adolescents?

2. If so, what components of self-compassion are the 'driving forces' behind the associations?

3. Are self-compassion levels similar among younger adolescents in middle school and older adolescents in high school?

4. Are self-compassion levels similar among males and females?

\section{Methods}

\section{Sample}

Two different groups of students were included in this study. The first group was drawn from a small, private middle school serving students in grades 6-8 situated in the suburban outskirts of a city in the southeast US. Once the school administration gave permission to conduct the study and the IRB provided approval, 24 of the 27 students attending the school turned in consent and assent forms. One student had medical issues and therefore dropped out of the study prior to its onset, leaving 23 participants. The final sample consisted of 12 males and 11 females, 13 of who were ages 11 and $12(57.5 \%)$ and 10 of who were ages 13 and 14 (43.4\%). All but two students were Caucasian (91.3\%); one was Asian (4.3\%) and one was Hispanic/Latino (4.3\%). Fifteen $(65.2 \%)$ of the students' mothers and $18(78.3 \%)$ of the students' fathers had graduate degrees, and only two (8.6\%) mothers and one father $(4.3 \%)$ did not have a college degree. Students completed an online survey prior to a mindfulness intervention; the data reported here are from this assessment.

Participants for the second group were recruited from a population of 9-12 grade public high school students in one high-school in the same city in the southeast. After permission was granted by the school district to administer the survey in the school library during nonclass hours, the IRB approved the study. Students were monitored by the librarians and first author to ensure they were taking the survey independently. Sixty-seven students turned in consent and assent forms and completed the online survey. Males constituted $41.8 \%$ of the sample, and females composed $58.2 \%$ of the sample, with $40.3 \%$ aged $14-15$ and $59.7 \%$ aged 16-18. The race/ethnicity of the students was 73.1\% Caucasian, $11.9 \%$ Black, 3\% Hispanic/Latino, $1.5 \%$ Asian, 1.5\% American Indian, and 9\% other. Roughly 34\% of the students' fathers had graduate degrees, and approximately $39 \%$ of students' mothers had graduate degrees. Only 3\% of students' mothers and 3\% of students' fathers had never attended college.

\section{Procedures}

The online survey consisted of the following measures:

Positive and negative affect-To measure the extent to which individuals experienced positive and negative affect during the past week, the 20-item PANAS scale was used (PANAS; Watson, Clark, \& Tellegen, 1988). Validated for adolescents (Crocker, 1997), the 
PANAS is composed of two subscales, which are positive affect and negative affect. This scale contains 10 emotion words that assess positive emotions and 10 words that assess negative emotions. Examples of positive emotion words are strong, inspired, and excited. Examples of negative emotion words are ashamed, upset, and afraid. Participants were asked to indicate how much they had experienced each of these emotions over the past few days. Participants indicated their responses to each item using a four-point scale ranging from 1 (very slightly or not at all) to 4 (most of the time). The two subscales have been shown to have a low correlation $(r=-0.22)$, to be internally consistent (Cronbach's $a=$ 0.84-0.87 for negative affect, and $0.86-0.90$ for positive affect) and to be stable over a twomonth time period ( $r=0.48$ for PA, $r=0.42$ for NA) (Watson et al., 1988). In addition, past research demonstrated evidence for both convergent and discriminant validity (Watson et al., 1988).

Self-compassion-Self-compassion was measured using the self-compassion scale, which is composed of 26 items (SCS; Neff, 2003b). The six subscales that comprise the selfcompassion scale are self-kindness ( 5 items, e.g. 'When I'm going through a very hard time, I give myself the caring and tenderness I need'); self-judgment (5 items, e.g. 'I'm disapproving and judgmental about my own flaws and inadequacies'); common humanity (4 items, e.g. 'When I feel inadequate in some way, I try to remind myself that feelings of inadequacy are shared by most people'); isolation (4 items, e.g. 'When I fail at something that's important to me, I tend to feel alone in my failure'); mindfulness (4 items, e.g. 'When something upsets me I try to keep my emotions in balance'); and over-identification (4 items, e.g. 'When I'm feeling down I tend to obsess and fixate on everything that's wrong'). Participants indicated their responses to each item using a five-point scale ranging from 1 (Almost Never) to 5 (Almost Always). Internal consistency for this scale was found to be excellent (Cronbach's $a=0.93$; Neff, 2003b). To establish construct validity, the selfcompassion scale was compared with related established scales, and was reported to have a negative correlation with the self-criticism subscale of the Depression Experience Questionnaire, a positive correlation with the Social Connectedness scale, and a positive correlation with the three subscales of the Trait-Meta Mood Scale which include attention, clarity, and repair (Neff, 2003b).

Life satisfaction-Global life satisfaction was measured using the Student's Life Satisfaction Scale (SLSS; Huebner, 1991). Global life satisfaction, a component of subjective well-being, refers to a judgment about one's well-being that is beyond that linked directly to well-being in specific domains (e.g. school, peers). Construct and discriminant validity were established through correlations with other well-being and affect scales, and comparisons to the correlations between similar scales in adults (Huebner, 1991). The seven-item scale has a unidimensional factor structure, adequate temporal stability over 1-2 weeks, and good internal consistency (Cronbach's $\alpha=0.82$; Huebner, 1991). Further validation, internal consistency and test-retest reliability over one year was established in a later study with a sample of 9th, 10th, 11th, and 12th graders (Huebner, Funk, \& Gilman, 2000). An example of an item is 'I have a good life'. Participants indicated their responses to each item using a four-point Likert-type scale ranging from 0 (never) to 3 (almost always). 
Perceived stress-Perceived stress was measured using the Perceived Stress Scale (PSS; Cohen, Kamarck, \& Mermelstein, 1983), a 14-item scale that is designed to assess the degree to which respondents find their lives 'unpredictable, uncontrollable, and overloading' (Cohen et al., 1983, p. 387). Theoretically, it reflects cognitive reappraisal theory (Lazarus, 1977), which emphasizes that it is the individual's personal and contextual appraisal of the event that is the chief determining factor in the resulting level of stress, rather than the nature of the objective event itself. An example of an item is, 'In the last month, how often have you been upset because of something that happened unexpectedly?' Participants indicated their responses to each item using a five-point Likert-type scale ranging from 0 (never) to 4 (very often). Content, predictive, and concurrent validity were established by Cohen and colleagues (1983). Construct validity for using this scale with adolescents was established in a study of adolescent psychiatric inpatients (Martin, Kazarian, \& Breiter, 1995).

In addition to these measures, an 8-item questionnaire of demographic information was included. This questionnaire asked about the participant's age, gender, race/ethnicity, parents' education, and factors related to socioeconomic status. Since adolescents often are not aware of their household income-level, questions were asked pertaining to number of computers or cars owned, number of vacations taken by students in the last year, and level of mother and father's education (or other adults in household) in order to access a general indication of SES.

\section{Results}

\section{Preliminary analyses}

Descriptive statistics-SPSS 20 was used for all statistical analyses with the exception of the subscale analyses; these regressions were conducted using SAS 9.2. Means and standard deviations were calculated for all scales in both school contexts and are reported in Table 1. Cronbach's $\alpha$ 's for scales were also computed for the middle-and high-school samples and were, respectively: 0.78, 0.83 (SCS); 0.72, 0.89 (NA); 0.87, 0.85 (PA); 0.79, 0.79 (PSS); and 0.79, 0.89 (SLSS).

Demographic variables-Independent t-tests were conducted to determine whether the two groups differed on any of the demographic variables. Results indicated no significant difference in number of cars $(M(\mathrm{SD})=3.57(0.90)$ vs. 3.67(1.19), middle vs. high school), computers (4.91(1.98) vs. 4.12(1.67), middle vs. high school), or vacations taken (3.22(1.20) vs. 2.73(1.30), middle vs. high school). However, there was a significant difference between the two groups in level of mother's education and level of father's education. The middleschool students had mothers and fathers with significantly more education than those of the high-school students (mothers' education: $t(88)=2.47, p=0.016$; fathers' education: $t(71)=$ $4.48, p<0.001)$. For this reason, both mother's education and father's education were entered as covariates in all regression analyses conducted.

Differences across developmental phase and gender groups-The two groups were combined into one data-set and a developmental phase (early adolescents and later adolescents) variable was created that was based on the two school contexts from which 
participants were recruited. Independent $t$-tests were then conducted first between males and females in each school context to determine if there was any difference in responses between the genders, and then across school contexts for each gender to determine if there was a difference between the males in middle school and those in high school, and between the females in middle school and those in high school. Results indicated that within the middle-school context, there were no significant differences on any measures between males and females. However, in the high-school context, there were significant differences between males and females on all dependent variables with the exception of positive affect (Table 1). High-school females scored significantly lower than males on the positive measures (self-compassion, life satisfaction) and higher than males on the negative measures (negative affect and perceived stress) reflecting a lower state of emotional well-being. This lower state of emotional health was apparent again when investigating the subscales of the self-compassion scale; although there were no significant differences on any of the positive subscales (self-kindness, common humanity and mindfulness), females scored higher on all the negative subscales (self-judgment, isolation and over-identification) than did their male counterparts in the high-school context (see Table 1).

When investigating scores of males and females separately across the two different school contexts, findings indicated no significant differences in dependent variables between males in middle school and those in high school. In relation to the self-compassion subscale scores, the only significant difference found was that males in high school had a greater sense of common humanity than did males in middle school. Results for females, however, told a different story. High-school females scored significantly lower than middle-school females on self-compassion and significantly higher on the negative dependent variables (perceived stress, negative affect). When the subscales for self-compassion were investigated, there were no significant differences between the two school contexts for females on the positively-worded subscales (self-kindness, mindfulness, and common humanity), but highschool females scored significantly higher on all the negatively-worded subscales than did females in middle school (self-judgment, isolation, over-identification; see Table 1).

\section{Primary analyses}

Associations with total self-compassion scores-To address the first research question regarding the relationship between self-compassion and dimensions of well-being in adolescents, partial correlations were calculated controlling for mother's education, father's education, school context, and gender. Results indicated that self-compassion demonstrated a significant association with all well-being measures except positive affect; the partial correlations for total self-compassion scores on dependent variables were: perceived stress $r(84)=-0.70, p<0.001$; negative affect $r(84)=-0.60, p<0.001$; life satisfaction $r(84)=0.51, p<0.001$; and positive affect $r(84)=0.06(\mathrm{~ns})$.

Associations with self-compassion subscale scores-To address the second research question regarding which components of self-compassion were the 'driving forces' behind the associations with well-being measures, hierarchical linear regressions were conducted. All possible regression models using the six subscales with each dependent variable were fit, and the optimal model for each was selected using the maximum adjusted 
$R^{2}$ as the criterion. All regressions controlled for mother's education, father's education, age, and gender. Results indicated that the optimal models for each dependent variable contained unique self-compassion components (see Table 2). In the model with negative affect as the dependent variable, the strongest association was with the component of isolation, followed closely by mindfulness, and over-identification was also included in the model. Compared with the models with negative affect, life satisfaction, and perceived stress as dependent variables, the model with positive affect as the dependent variable was weaker overall (Adj. $\left.R^{2}=0.105\right)$, and the two self-compassion components in this model were nonsignificant: common humanity: $\beta=1.07, t=1.49$ (ns) and over-identification: $\beta=-1.26, t=-1.70$ (ns). The model with perceived stress as the dependent variable included four self-compassion components (i.e. isolation, over-identification, mindfulness, and common humanity), with isolation having the strongest association. Similarly, in the optimal model with life satisfaction as the dependent variable, the components included were isolation, common humanity, and over-identification, and isolation had the greatest beta weight. Taking a broad view and looking across dependent variables, the component of over-identification appeared in the optimal model for each dependent variable. Isolation and common humanity appeared in three of the four optimal models, and mindfulness appeared in two of the optimal models. Self-kindness and self-judgment did not appear in any of the models. Most notably, isolation had the greatest beta value in three of the four optimal models, the fourth model representing the weaker association between self-compassion and positive affect. Further, all associations were in the expected directions as indicated by standardized regression coefficients, e.g. isolation and over identification had positive associations with negative affect and perceived stress, and an inverse relationship with life satisfaction. Common humanity had positive associations with positive affect and life satisfaction, and an inverse relationship with perceived stress (see Table 2).

To address whether developmental phase (the third research question) or gender (the fourth research question) moderated the associations between the self-compassion subscales and the well-being measures, two different interaction variables were created for each sub-scale, one by multiplying the centered self-compassion subscale by developmental phase, and one by multiplying it by gender. The first model tested age as a moderator, and the second tested gender as a moderator, while controlling for mother's education and father's education in both models. This same procedure was followed with each of the self-compassion subscales and each of the dependent variables (positive affect, negative affect, perceived stress, and life satisfaction) in a series of regression analyses. For example, when investigating developmental phase as a moderator between self-kindness and negative affect, gender was controlled along with mother's and father's educational levels, and when gender was investigated as a potential moderator in the relationship, developmental phase was controlled, along with mother and father's educational levels. Findings indicated that developmental phase moderated the associations between positive affect and the following components of self-compassion: self-judgment $(\beta=-0.94, t(83)=-2.92, p=0.005)$, common humanity $(\beta=-0.71, t(83)=-2.38, p=0.02)$, isolation $(\beta=-1.02, t(83)=-3.24, p=$ $0.002)$, mindfulness $(\beta=-1.08, t(83)=-3.79, p<0.001)$, and over-identification $(\beta=-0.99$, $t(83)=-2.95, p=0.004)$. These findings suggest that the negatively worded components of self-compassion were associated to a greater degree with lower positive affect in older 
adolescents than they were for early adolescents. Moreover, the positively worded subscales had greater associations with positive affect among early adolescents (middle school) than among older adolescents (high school). The results of the regression analyses conducted using gender as a moderator indicated that gender did not moderate any of the associations between the self-compassion subscales and the dependent variables. This latter finding was consistent with results reported in a recent meta-analysis of research conducted with adults (MacBeth \& Gumley, 2012).

Finally, to get an overall view of the effects of gender and phase of adolescence on the association between self-compassion and the dependent variables, the identical procedure was followed using the total self-compassion score. The four dependent variables were regressed sequentially on self-compassion using developmental phase and gender as moderators, controlling for mother's and father's educational levels. Again, gender did not moderate any of the relationships between self-compassion and the dependent variables. Developmental phase, however, did moderate the inverse association between selfcompassion and negative affect $(\beta=-0.65, t(83)=-2.62, p=0.01)$ suggesting that as adolescents get older, the inverse association between total self-compassion and negative affect strengthens.

\section{Discussion}

Self-compassion has been minimally studied in adolescence, although it has been associated with positive emotional well-being among adults in a number of studies (MacBeth \& Gumley, 2012). The present study extends our understanding of self-compassion by specifically investigating self-compassion in an adolescent population. Further, it goes beyond previous research by examining the associations of components of self-compassion with dimensions of emotional well-being among adolescents. Additionally, it investigates how developmental phase of adolescence and gender might moderate these associations.

First, mean scores of self-compassion demonstrated that although there was no significant difference between males and females in early adolescence, in later adolescence (high school) females' self-compassion scores were lower, and differed significantly both from males in high school and females in middleschool. This finding is contrary to that of Neff and McGehee (2010) who reported no differences in self-compassion scores between males and females of high-school age (14-17 year olds). Moreover, it appears that the components of self-compassion driving this decrease were the negatively worded subscales of the selfcompassion scale. Thus, high-school females reported being more self-judging, feeling more isolated, and having more difficulty maintaining a balanced perspective in the midst of challenging circumstances than either males of the same phase of adolescence or younger adolescent females. These results are congruent with self-compassion research with adults in which females also have been found to have lower self-compassion than males (Neff, 2003b; Neff \& Beretvas, 2013; Neff \& McGehee, 2010; Neff \& Vonk, 2009; Raes, 2010; Yarnell \& Neff, 2013).

Recognizing that there exists significant associations between self-compassion and dimensions of emotional well-being, this new finding which elucidates the incidence of 
lower self-compassion among older high-school females is consistent with research that has found depression in adolescent females to be greater than that of males, and that this difference begins to emerge between the ages of 13 and 15 and reaches the greatest gap between the ages of 15 and 18 (Hankin, Abramson, Moffitt, Silva, \& McGee, 1998). Further, in a longitudinal study of depression during the transition from early to middle adolescence, findings supported the conclusion that rumination moderated the association between the occurrence of negative events and the development of subsequent depressive symptoms and major depressive episodes. Rumination was defined as responses to depressed moods that were compulsively self-focused on experiences of one's distress (Abela \& Hankin, 2011). Thus, rumination was conceptualized as a vulnerability factor to depression and it was suggested that gender differences in rumination may emerge as a consequence of, rather than a cause of, gender differences in adolescents over time. Insofar as self-compassion has been reported to be inversely associated with rumination in adults (Neff, 2003b; Neff et al., 2007), the role of self-compassion in general, and of selfjudgment, isolation, and over-identification specifically, needs to be examined longitudinally in adolescents to assess if they are causes or consequences of diminished emotional well-being.

\section{Developmental phase and gender as moderators}

In relation to whether developmental phase of adolescence or gender moderated the associations between self-compassion and well-being, results indicated that gender did not significantly moderate any of the associations between either the subscales of selfcompassion and well-being variables or the total self-compassion score and total scores for the well-being variables. It appeared that although females in high school reported lower self-compassion, the extent to which self-compassion and well-being were linked was not significantly different for males and females. In contrast, developmental phase of adolescence did moderate the association between negative affect and overall selfcompassion, as well as between positive affect and the self-compassion components of selfjudgment, common humanity, isolation, mindfulness, and over-identification. It may be that as adolescents get older, the effects of self-compassion, or lack thereof, on negative affect increase. Thus, although higher self-compassion was associated with less negative affect in both early and later adolescents, the effect of less self-compassion on negative affect for older adolescents was stronger. Furthermore, among older adolescents, the association of the negatively worded subscales of self-compassion on positive affect strengthened. The negatively worded subscales (self-judgment, isolation, and over-identification) were associated with a greater decrease in positive affect among older adolescents than they were with younger adolescents. The positive sub-scales of common humanity and mindfulness were associated with an increase in positive affect to a greater extent than they were among younger adolescents. It is possible that this moderation effect emerges for positive affect (rather than the other well-being variables) because it is a weak association, and is therefore perhaps more sensitive to being influenced by another variable, such as developmental phase of adolescence. 


\section{Influence of components of self-compassion}

When the most optimal and parsimonious regression models with all subscales and dependent variables were examined, the components of self-compassion that were associated most strongly with the dependent variables were over-identification, isolation, mindfulness, and common humanity. The component with the most consistent and strongest associations was isolation. It appears that feeling isolated and disconnected from others is related to negative mood, perceived stress, and less satisfaction with life among this group of adolescents. It is conceivable that this sense of isolation is related to the phenomena of the 'personal fable', in which adolescents see their experiences as unique. Additionally, both mindfulness and over-identification, two components that measure a similar phenomenon (but with reverse wording), were found to be related to negative mood and stress in the expected directions. This finding suggests that if adolescents were able to keep a more balanced perspective when experiencing difficulties, they might be better able to face everyday experiences with less stress and improved mood. In addition, although common humanity was inversely related to perceived stress and less strongly related to positive affect, its most prominent role emerged in its relationship to life satisfaction. Understanding that we are integrally connected with others through our shared human experience seems to contribute strongly to how satisfied teens are with their lives.

Interestingly, self-kindness and self-judgment did not emerge as significant correlates in any of the optimal models. This was surprising, as most of the current literature reports at least one of these components as associated with emotional health. For example, Van Dam and colleagues (2011) found self-judgment and isolation to be correlated with psychological health, and Ying (2009) found all the subscales with the exception of common humanity to be associated with depression in the expected directions. What might account for the difference in these findings?

The above examples, as well as numerous other studies, utilized adult samples. The results presented here are the first that examined self-compassion subscales among an adolescent sample. It is possible that feeling isolated and ruminating or catastrophizing when faced with diffi-cult circumstances are particularly characteristic of the adolescent phase, and as individuals get older and moves into adulthood, the tendency to 'over-dramatize' and feel alone in one's challenges becomes less pronounced. Lending support to this, Hollis-Walker and Colosimo (2011) also found isolation to emerge as the only signifi-cant component associated with positive well-being in a sample of young adults. Although this sample was somewhat older than that of the present study, 84\% of the sample was between 18 and 24, and therefore closer in age to that of the present study than most other studies that have examined subscales.

It is important to recognize, however, that research with self-compassion subscales is in its infancy and more work still needs to be conducted in this area before any definitive conclusions can be drawn. 


\section{Limitations}

This study has a number of limitations. The sample size was small, particularly for the middle-school group. In addition, the two developmental phase groups came from different school contexts. Although the differing between-school demographics were controlled, it is possible that there were other differences that were not measured. Also, it should be noted that students from both schools came from families in which parents were very welleducated; in the middle school, roughly three-fourths of the parents had graduate degrees, and in the high school roughly one-third had graduate degrees. This limits the degree to which these results can be generalized to other adolescent populations. Future research should be conducted with a larger sample, including both similar and diverse school sites. Additionally, to investigate changes across adolescence more clearly, it would be necessary to conduct a longitudinal study with adolescents, measuring self-compassion and other variables from early adolescence to later adolescence. Such an approach to future research would offer a wealth of information about self-compassion and emotional well-being during the adolescent years.

\section{Implications for self-compassion interventions}

What can be done, then, to address this comparatively lower level of self-compassion that adolescents, particularly females, report in mid to late adolescence? Although these data are cross-sectional and therefore we cannot determine the direction of effects, one interpretation of the results is that developing greater self-compassion may help enhance adolescents' emotional well-being. Interventions to address the development of greater self-compassion need to begin in the early adolescent years to subvert the apparent decline in selfcompassion that occurs in mid-adolescence to late-adolescence. A training program in developing self-compassion, designed specifically for teens, could be of significant value in bolstering and preventing this decline of self-compassion. Mindful Self-Compassion, a pilot eight-week self-compassion enhancing program for adults, reported increases in selfcompassion, life satisfaction, compassion for others, and decreases in depression, anxiety, stress, and avoidance in pre-test to post-test assessments (Neff \& Germer, 2012). A parallel program designed specifically for adolescents may offer promise in teaching adolescents ways in which they can be aware of situations that are challenging, and how they can offer themselves kindness in these situations. In particular, it would seem that helping females recognize that their suffering is part of their growth process, and that it is highly prevalent among adolescent females, could help decrease stress, sense of isolation, and engender selfcompassion and self-care. The development of such a program would, therefore, contribute to alleviating the emotional challenges frequently encountered by adolescents in this developmental phase, and facilitate their growth into healthy, compassionate adults.

The positive psychology movement recognizes factors that promote flourishing and resilience. Through its associations with well-being, self-compassion can therefore be considered as one such factor. Prior to the present study, self-compassion had been minimally studied in adolescent samples. This study therefore advances our understanding of self-compassion and its role in positive psychology by elucidating the differences in selfcompassion across phases of adolescence and between genders, and the ensuing associations with well-being. 


\section{Acknowledgements}

We gratefully acknowledge Susan Gaylord, PhD, Director of the University of North Carolina-Chapel Hill Program on Integrative Medicine, for her contributions in editing this manuscript.

Funding

Funding was provided in part by [grant number T32AT003378-04] from the National Center on Complementary and Alternative Medicine (NCCAM) at the National Institutes of Health (NIH). Analyses and conclusions are the responsibility of the authors rather than the funders.

\section{References}

Abela JRZ, Hankin BL. Rumination as a vulnerability factor to depression during the transition from early to middle adolescence: A multiwave longitudinal study. Journal of Abnormal Psychology. 2011; 120:259-271. [PubMed: 21553940]

Albano, AM.; Chorpita, BF.; Barlow, DH. Childhood anxiety disorders.. In: Mash, EJ.; Barkley, RA., editors. Child Psychopathology. Guilford Press; New York, NY: 2003. p. 279-329.

Allen AB, Goldwasser ER, Leary MR. Self-compassion and well-being among older adults. Self and Identity. 2012; 11:428-453. [PubMed: 23525647]

Arnett, JJ. Adolescence and emerging adulthood: A cultural approach. Prentice-Hall; Upper Saddle River, NJ: 2001.

Baer, RA. Mindfulness-and acceptance-based interventions and processes of change.. In: Baer, R., editor. Assessing mindfulness and acceptance processes in clients: Illuminating the theory and practice of change. New Harbinger Press; Oakland, CA: 2010. p. 135-154.

Baer RA, Lykins ELB, Peters JR. Mindfulness and self-compassion as predictors of psychological wellbeing in long-term meditators and matched nonmeditators. The Journal of Positive Psychology. 2012; 7:230-238. doi:10.1080/17439760.2012.674548.

Barnard LK, Curry JF. The relationship of clergy burnout to self-compassion and other personality dimensions. Pastoral Psychology. 2011; 61:149-163.

Blakemore, J.; Berenbaum, S.; Liben, L. Gender development. Psychology Press; Clifton, NJ: 2009.

Breines JG, Chen S. Self-compassion increases self-improvement motivation. Personality and Social Psychology Bulletin. 2012; 38:1133-1143. [PubMed: 22645164]

Brooks M, Kay-Lambkin F, Bowman J, Childs S. Self-compassion amongst clients with problematic alcohol use. Mindfulness. 2012; 3:308-317.

Cohen S, Kamarck T, Mermelstein R. A global measure of perceived stress. Journal of Health and Social Behavior. 1983:385-396. [PubMed: 6668417]

Crocetti E, Klimstra T, Keijsers L, Hale WW, Meeus W. Anxiety trajectories and identity development in adolescence: A five-wave longitudinal study. Journal of Youth and Adolescence. 2009; 38:839849. [PubMed: 19636785]

Crocker PRE. A confirmatory factor analysis of the positive affect negative affect schedule (PANAS) with a youth sport sample. Journal of Sport and Exercise Psychology. 1997; 19:91-97.

Divall S, Radovick S. Pubertal development and menarche. Annals of the New York Academy of Sciences. 2008; 1135:19-28. [PubMed: 18574204]

Elkind D. Egocentrism in adolescence. Child Development. 1967; 38:1025-1034. [PubMed: 5583052]

Elkind D. Understanding the young adolescent. Adolescence. 1978; 13:127-134.

Elkind D. Egocentrism redux. Developmental Review. 1985; 5:218-226.

Erikson, E. Identity: Youth in crisis. Norton; New York, NY: 1968.

Froh JJ, Kashdan TB, Yurkewicz C, Fan J, Allen J, Glowacki J. The benefits of passion and absorption in activities: Engaged living in adolescents and its role in psychological well-being. The Journal of Positive Psychology. 2010; 5:311-332.

Giedd J. The teen brain: Insights from neuroimaging. Journal of Adolescent Health. 2008; 42:321-323. [PubMed: 18346654] 
Hammon, C.; Rudolph, K. Childhood mood disorders.. In: Mash, EJ.; Barkley, RA., editors. Child psycho-pathology. Guilford Press; New York, NY: 2003. p. 233-278.

Hankin B, Abramson L, Moffitt T, Silva P, McGee R. Development of depression from preadolescence to young adulthood: Emerging gender differences in a 10-year longitudinal study. Journal of Abnormal Psychology. 1998; 107:128-140. [PubMed: 9505045]

Heffernan M, Quinn Griffin MT, McNulty SR, Fitzpatrick JJ. Self-compassion and emotional intelligence in nurses. International Journal of Nursing Practice. 2010; 16:366-373. [PubMed: 20649668]

Hollis-Walker L, Colosimo K. Mindfulness, self-compassion, and happiness in non-meditators: A theoretical and empirical examination. Personality and Individual Differences. 2011; 50:222-227.

Howell, AJ.; Keyes, CLM.; Passmore, HA. Flourishing among children and adolescents: Structure and correlates of positive mental health, and interventions for its enhancement.. In: Proctor, C.; Linley, PA., editors. Research, applications, and interventions for children $\&$ adolescents: A positive psychology perspective. Springer; New York, NY: 2013. p. 59-80.

Hoyt LT, Chase-Lansdale PL, McDade TW, Adam EK. Positive youth, healthy adults: Does positive well-being in adolescence predict better perceived health and fewer risky health behaviors in young adulthood? Journal of Adolescent Health. 2012; 50:66-73. [PubMed: 22188836]

Huebner ES. Initial development of the student's life satisfaction scale. School Psychology International. 1991; 12:231-240.

Huebner ES, Funk BA, Gilman R. Cross-sectional and longitudinal psychosocial correlates of adolescent life satisfaction reports. Canadian Journal of School Psychology. 2000; 16:53-64.

Iskender M. The relationship between self-compassion, self-efficacy, and control belief about learning in Turkish university students. Social Behavior and Personality: An International Journal. 2009; 37:711-720.

Johnson LE, Greenberg MT. Parenting and early adolescence internalizing: The importance of teasing apart anxiety and depressive symptoms. The Journal of Early Adolescence. 2013; 33:201-226. [PubMed: 24027352]

Kashani JH, Orvaschel H. A community study of anxiety in children and adolescents. American Journal of Psychiatry. 1990:201-226.

Keating, D. Cognitive and brain development.. In: Lerner, R.; Steinberg, L., editors. Handbook of adolescent psychology. 2nd ed.. Wiley; New York, NY: 2004. p. 45-84.

Kessler RC, Avenevoli S, Ries Merikangas K. Mood disorders in children and adolescents: An epidemiologic perspective. Biological Psychiatry. 2001; 49:1002-1014. [PubMed: 11430842]

Keyes CLM, Dhingra SS, Simoes EJ. Change in level of positive mental health as a predictor of future risk of mental illness. American Journal of Public Health. 2010; 100:2366-2371. [PubMed: 20966364]

Lazarus, R. Psychological stress and coping in adaptation and illness.. In: Lipowski, Z.; Lipsi, D.; Whybrow, P., editors. Psychosomatic medicine: Current trends. Oxford University Press; New York, NY: 1977. p. 14-26.

Leary MR, Tate EB, Adams CE, Batts Allen AB, Hancock J. Self-compassion and reactions to unpleasant self-relevant events: The implications of treating oneself kindly. Journal of Personality and Social Psychology. 2007; 92:887-904. [PubMed: 17484611]

Lewinsohn PM, Hops H, Roberts RE, Seeley JR, Andrews JA. Adolescent psychopathology: I. Prevalence and incidence of depression and other DSM-III-R disorders in high school students. Journal of Abnormal Psychology. 1993; 102:133-144. [PubMed: 8436689]

MacBeth A, Gumley A. Exploring compassion: A meta-analysis of the association between selfcompassion and psychopathology. Clinical Psychology Review. 2012; 32:545-552. [PubMed: 22796446]

Marcia, JE. Identity in adolescence.. In: Adelson, J., editor. Handbook of adolescent psychology. Wiley and Sons; New York, NY: 1980. p. 159-187.

Martin RA, Kazarian SS, Breiter HJ. Perceived stress, life events, dysfunctional attitudes, and depression in adolescent psychiatric inpatients. Journal of Psychopathology and Behavioral Assessment. 1995; 17:81-95. 
Mills A, Gilbert P, Bellew R, McEwan K, Gale C. Paranoid beliefs and self-criticism in students. Clinical Psychology and Psychotherapy. 2007; 14:358-364.

Neff KD. Self-compassion: An alternative conceptualization of a healthy attitude toward oneself. Self and Identity. 2003a; 2:85-101.

Neff KD. The development and validation of a scale to measure self-compassion. Self and Identity. 2003b; 2:223-250.

Neff KD, Beretvas SN. The role of self-compassion in romantic relationships. Self and Identity. 2013; 12:78-98.

Neff, KD.; Dahm, KA. Self-compassion: What it is, what it does, and how it relates to mindfulness.. In: Robinson, M.; Meier, B.; Ostafin, B., editors. Mindfulness and self-regulation. Springer; New York, NY: in press

Neff KD, Germer C. A pilot study and randomized controlled trial of the mindful self-compassion program. Journal of Clinical Psychology. 2012; 1:1-17.

Neff KD, Hsieh Y, Dejitterat K. Self-compassion, achievement goals, and coping with academic failure. Self and Identity. 2005; 4:263-287.

Neff KD, Kirkpatrick KL, Rude SS. Self-compassion and adaptive psychological functioning. Journal of Research in Personality. 2007; 41:139-154.

Neff KD, McGehee P. Self-compassion and psychological resilience among adolescents and young adults. Self and Identity. 2010; 9:225-240.

Neff KD, Pommier E. The relationship between self-compassion and other-focused concern among college undergraduates, community adults, and practicing meditators. Self and Identity. 2013; 12:160-176.

Neff KD, Vonk R. Self-compassion versus global self-esteem: Two different ways of relating to oneself. Journal of Personality. 2009; 77:23-50. [PubMed: 19076996]

Nolen-Hoeksema S. Gender differences in depression. Current Directions in Psychological Science. 2001; 10:173-176.

Raes F. Rumination and worry as mediators of the relationship between self-compassion and depression and anxiety. Journal of Personality and Individual Differences. 2010; 48:757-761.

Seligman, ME. Flourish: A visionary new understanding of happiness \& well-being. Free Press; New York, NY: 2012.

Seligman ME, Csikzentmihalyi M. Positive psychology: An introduction. American Psychologist. 2000; 55:5-14. [PubMed: 11392865]

Steinberg, L. Adolescence. McGraw Hill-College; Boston, MA: 1999.

Susman, E.; Dorn, L. Puberty: Its role in development.. In: Lerner, RM.; Steinberg, L., editors. Handbook of adolescent psychology. 3rd ed.. Wiley; New York, NY: 2009. p. 116-151.

Thapar A, Collinshaw S, Pine DS, Thapar AK. Depression in adolescence. Lancet. 2012; 379:10651067.

Van Dam NT, Sheppard SC, Forsyth JP, Earleywine M. Self-compassion is a better predictor than mindfulness of symptom severity and quality of life in mixed anxiety and depression. Journal of Anxiety Disorders. 2011; 25:123-130. [PubMed: 20832990]

Watson D, Clark L, Tellegen A. Development and validation of brief measures of positive and negative affect: The PANAS scales. Journal of Personality and Social Psychology. 1988; 54:10631070. [PubMed: 3397865]

Wong CC, Mak WW. Differentiating the role of three self-compassion components in buffering cognitive-personality vulnerability to depression among Chinese in Hong Kong. Journal of Counseling Psychology. 2012; 60:162-169. [PubMed: 23088681]

Yarnell LM, Neff KD. Self-compassion, interpersonal conflict resolutions, and well-being. Self and Identity. 2013; 12:146-159.

Ying Y-W. Contribution of self-compassion to competence and mental health in social work students. Journal of Social Work Education. 2009; 45:309-323. 


\section{Table 1}

Comparisons of male and female middle- and high-school students on emotional well-being variables and selfcompassion subscales.

\begin{tabular}{|c|c|c|c|c|c|c|c|c|}
\hline \multirow[b]{3}{*}{ Scale } & \multicolumn{2}{|c|}{ Middle school $M$ (SD) } & \multicolumn{2}{|c|}{ High school $M(\mathrm{SD})$} & \multirow{2}{*}{\multicolumn{2}{|c|}{$\begin{array}{c}t \text {-test for middle } \\
\text { school vs. high } \\
\text { school } \\
\end{array}$}} & \multicolumn{2}{|c|}{$t$-test for males vs. females } \\
\hline & \multirow[b]{2}{*}{$\begin{array}{r}\text { Males }(n= \\
12)\end{array}$} & \multirow[b]{2}{*}{$\begin{array}{r}\text { Females }(n \\
=11)\end{array}$} & \multirow[b]{2}{*}{$\begin{array}{r}\text { Males }(n= \\
28)\end{array}$} & \multirow[b]{2}{*}{$\begin{array}{r}\text { Females }(n \\
=39)\end{array}$} & & & \multirow[b]{2}{*}{ Middle school } & \multirow[b]{2}{*}{ High school } \\
\hline & & & & & Males & Females & & \\
\hline Total Self-compassion & $2.98(0.71)$ & $3.32(0.52)$ & $3.25(0.48)$ & $2.78(0.50)$ & 0.206 & $3.15^{* *}$ & -1.3 & $3.87^{* * *}$ \\
\hline Negative affect & $20.00(6.16)$ & $19.64(4.39)$ & $22.25(8.20)$ & $28.56(8.51)$ & -0.852 & $-3.34^{* *}$ & 0.16 & $-3.04^{* *}$ \\
\hline Positive affect & $33.75(9.53)$ & $34.64(5.32)$ & $37.65(6.12)$ & $34.90(6.44)$ & -1.55 & -0.12 & -0.27 & 1.76 \\
\hline Perceived stress & $22.75(9.07)$ & $22.55(5.16)$ & $25.80(7.79)$ & $31.29(7.44)$ & -1.08 & $-3.65^{* *}$ & 0.07 & $-2.92^{* *}$ \\
\hline Life satisfaction & $2.89(0.66)$ & $2.81(0.53)$ & $3.17(0.71)$ & $2.57(0.68)$ & -1.14 & 1.05 & 0.35 & $3.45^{* *}$ \\
\hline Self-kindness & $2.43(1.30)$ & $2.95(0.92)$ & $2.87(0.80)$ & $2.76(0.68)$ & -1.17 & 0.96 & -1.2 & 0.63 \\
\hline Self-judgment & $2.57(1.13)$ & $2.11(1.19)$ & $2.54(1.01)$ & $3.44(0.80)$ & -0.37 & $-3.82^{* * *}$ & 0.14 & $-4.06^{* * *}$ \\
\hline Common humanity & $2.08(1.26)$ & $2.93(1.29)$ & $3.00(1.21)$ & $3.01(0.72)$ & $-2.27^{*}$ & -0.39 & -2.00 & -0.05 \\
\hline Isolation & $2.40(1.22)$ & $2.39(1.00)$ & $2.70(0.98)$ & $3.21(0.80)$ & -0.28 & $-2.69^{*}$ & 0.32 & $-2.32^{*}$ \\
\hline Mindfulness & $2.56(1.13)$ & $3.16(0.90)$ & $3.44(0.97)$ & $3.11(0.78)$ & -1.47 & -0.17 & -0.39 & 1.52 \\
\hline Over-identification & $2.46(1.11)$ & $2.07(0.69)$ & $2.58(1.07)$ & $3.48(0.68)$ & 0.22 & $-5.78^{* * *}$ & 1.31 & $-3.91^{* * *}$ \\
\hline \multicolumn{9}{|l|}{$*<0.05$ (2-tailed) } \\
\hline \multicolumn{9}{|l|}{$* * x<0.01$ (2-tailed) } \\
\hline$* * * x<0.001$ (2-tailed). & & & & & & & & \\
\hline
\end{tabular}




\section{Table 2}

Hierarchical regression coefficients for well-being variables regressed on self-compassion subscales controlling for age, gender, and mother's and father's education.

\begin{tabular}{|c|c|c|c|c|c|}
\hline & $\beta$ & SE $\beta$ & $B$ & $t$ & $p$ \\
\hline \multicolumn{6}{|c|}{ Negative affect: Adj. $R^{2}=0.501$} \\
\hline Isolation & 3.75 & 0.94 & 0.41 & 3.97 & 0.0002 \\
\hline Mindfulness & -3.34 & 0.72 & -0.36 & -4.62 & $<0.0001$ \\
\hline Over-identification & 1.64 & 0.91 & 0.19 & 1.81 & 0.07 \\
\hline \multicolumn{6}{|c|}{ Positive affect: Adj. $R^{2}=0.105$} \\
\hline Common humanity & 1.07 & 0.72 & 0.16 & -4.62 & 0.14 \\
\hline Over-identification & -1.26 & 0.74 & -0.18 & -1.70 & 0.09 \\
\hline \multicolumn{6}{|c|}{ Perceived stress: Adj. $R^{2}=0.639$} \\
\hline Isolation & 4.23 & 0.78 & 0.48 & 5.42 & $<0.0001$ \\
\hline Mindfulness & -2.30 & 0.77 & -0.26 & -2.96 & 0.004 \\
\hline Over-identification & 2.31 & 0.75 & 0.28 & 3.07 & 0.003 \\
\hline Common humanity & -1.24 & 0.73 & -0.15 & -1.69 & 0.09 \\
\hline \multicolumn{6}{|c|}{ Life satisfaction: Adj. $R^{2}=0.413$} \\
\hline Common humanity & 0.21 & 0.06 & 0.29 & 3.41 & 0.001 \\
\hline Isolation & -0.25 & 0.09 & -0.33 & -2.96 & 0.004 \\
\hline Over-identification & -0.10 & 0.08 & -0.14 & -1.22 & 0.23 \\
\hline
\end{tabular}

